\title{
The Ideal Time for Iron Administration in Anemia Secondary to Blood Loss-An Experimental Animal Model
}

\author{
Mirela Tiglis ${ }^{1,2}$, Ileana Peride $\left.{ }^{3}{ }^{(}\right)$, Lucian Cristian Petcu ${ }^{4}$, Tiberiu Paul Neagu ${ }^{5,6, *}$, Andrei Niculae ${ }^{3}$ (D), \\ Alexandra Totan $7 \oplus$, Sabina Andrada Zurac ${ }^{8,9}$, Ionel Alexandru Checherita ${ }^{3}\left(\mathbb{D}\right.$ ) and Ioana Marina Grintescu ${ }^{1,2}$
}

check for updates

Citation: Tiglis, M.; Peride, I.; Petcu, L.C.; Neagu, T.P.; Niculae, A.; Totan,

A.; Zurac, S.A.; Checherita, I.A.; Grintescu, I.M. The Ideal Time for Iron Administration in Anemia Secondary to Blood Loss-An Experimental Animal Model. Life 2021, 11, 898. https://doi.org/ 10.3390/life11090898

Academic Editors: Claudia Neunaber, Milena Fini and Paolo Cinelli

Received: 3 August 2021

Accepted: 27 August 2021

Published: 30 August 2021

Publisher's Note: MDPI stays neutral with regard to jurisdictional claims in published maps and institutional affiliations.

Copyright: (c) 2021 by the authors. Licensee MDPI, Basel, Switzerland. This article is an open access article distributed under the terms and conditions of the Creative Commons Attribution (CC BY) license (https:/ / creativecommons.org/licenses/by/ $4.0 /)$.
1 Department of Anesthesiology and Intensive Care, "Carol Davila" University of Medicine and Pharmacy, 020021 Bucharest, Romania; mirelatiglis@gmail.com (M.T.); ioana.grintescu@umfcd.ro (I.M.G.)

2 Department of Anesthesiology and Intensive Care, Emergency Clinical Hospital, 014461 Bucharest, Romania

3 Department of Nephrology and Dialysis, "Carol Davila" University of Medicine and Pharmacy, 020021 Bucharest, Romania; ileana_peride@yahoo.com (I.P.); niculaeandrei@yahoo.com (A.N.); al.checherita@gmail.com (I.A.C.)

4 Department of Biophysics and Biostatistics, Faculty of Dentistry, “Ovidius" University, 900684 Constanta, Romania; petculucian@univ-ovidius.ro

5 Department of Plastic Surgery and Reconstructive Microsurgery, “Carol Davila” University of Medicine and Pharmacy, 020021 Bucharest, Romania

6 Department of Plastic Surgery and Reconstructive Microsurgery, Emergency Clinical Hospital of Bucharest, 014461 Bucharest, Romania

7 Department of Biochemistry, Faculty of Dental Medicine, "Carol Davila" University of Medicine and Pharmacy, 020021 Bucharest, Romania; alexandra.totan@umfcd.ro

8 Department of Pathology, “Colentina” Clinical Hospital, 020125 Bucharest, Romania; sabina.zurac@umfcd.ro

9 Department of Pathology, Faculty of Dental Medicine, "Carol Davila" University of Medicine and Pharmacy, 020021 Bucharest, Romania

* Correspondence: dr.neagupaul@gmail.com; Tel.: +4021-599-23-00

Abstract: Background: Anemia and iron deficiency are two of the main public health problems worldwide, associated with negative outcomes in surgical patients. This experimental study aimed to create a model of acute iron deficiency with anemia through blood loss and extensive surgery. Afterwards, intravenous iron was administered to correct the iron deficiency and to improve the hematological parameters in distinct moments regarding the surgical time. To assess the optimum time for therapeutic intervention, experimental subjects were compared, performing clinical, paraclinical, and histological examinations, as well. Methods: Male rats $(n=35)$, aged $11-13$ months, were randomly designated into six groups. Anemia and iron deficiency were obtained through a $15 \%$ blood volume loss, followed by major surgical intervention (femur fracture and osteosynthesis using Kirschner wire). Therapeutic intervention was obtained with an intravenous ferric carboxymaltose infusion, as follows: group II: intraoperative $(n=7)$, group III: $48 \mathrm{~h}$ after surgery $(n=7)$, group IV: $48 \mathrm{~h}$ before surgery $(n=5)$, and group V: seven days before surgery $(n=6)$. Group I $(n=5)$ was left anemic, while group $0(n=5)$ was nonanemic without therapeutic intervention. Results and Discussion: In group I, serum iron lower than in group $0(27.04 \pm 6.92 \mu \mathrm{g} / \mathrm{dL}$ versus $60.5 \pm 2.34 \mu \mathrm{g} / \mathrm{dL})$, as well as hemoglobin $(10.4 \pm 0.54 \mathrm{~g} / \mathrm{dL}$ versus $14.32 \pm 2.01 \mathrm{~g} / \mathrm{dL})$ and ferritin values $(22.52 \pm 0.53 \mathrm{ng} / \mathrm{mL}$ versus $29.86 \pm 3.97 \mathrm{ng} / \mathrm{mL}$ ), validated the experimental model. Regarding wound healing after surgical trauma, we observed that neovascularization was more significant in group III, followed by group V, with fewer neutrophils, a well-represented and rich in lymphomonocytes inflammatory infiltrate associated with the biggest collagen fiber dimensions. The periosteal reaction and callus area presented thicker trabeculae in groups II and III compared to the anemic group. Conclusions: This original experimental study assessed the effect of perioperative intravenous iron administration at a specific time by comparing the weight, hematological, and iron status-defining parameters, as well as histological characteristics of the included subjects. The present findings highlight that correcting the iron deficiency in emergency settings through intravenous iron administration intraoperatively or $48 \mathrm{~h}$ postoperatively could determine the improved bioumoral parameters, as well as a better evolution of the postoperative wound and bone healing compared to the anemic group or subjects that received therapeutic intervention $48 \mathrm{~h}$ before surgery. 
Keywords: experimental model; rats; acute bleeding; iron deficiency; intravenous iron; healing

\section{Introduction}

Anemia and iron deficiency, despite being intensively explored, are two of the main public health problems worldwide, with certain negative impacts in hospitalized patients. Regarding anemia, its prevalence is about $26-75 \%$ in the preoperative period, reaching even the threshold of $90 \%$ postoperatively [1,2]. Iron deficiency is one of the leading causes of anemia in patients, a consequence of important blood losses, extensive surgeries, and poor gastrointestinal tolerance aggravated by the lack of time to perform a preoperative therapeutic intervention to optimize the hematological status $[3,4]$.

For this reason, intravenous iron agents have been thoroughly researched and improved over the years [5] in order to be used as an alternative to a blood transfusion, a temporary measure, associated with various complications, in this subgroup of patients [6]. These new iron-containing agents have a safe profile, with stable molecules, which allows the administration of large amounts in a single infusion through a short period associated with fewer adverse events [5,7].

Various studies have shown the undisputed role of preoperative intravenous iron used for hemoglobin correction in patients undergoing elective surgeries [8-10]. Current practice involves correcting anemia ahead of selective major surgery, preferably for at least 30 days, knowing the negative causal relationship between anemia and postoperative outcome (increased morbidity and mortality, increased length of stay in the hospital, and increased rate of cardiovascular events) [1,10]. Regarding the immediate perioperative period when there is no time to properly correct anemia before surgery, the ideal moment for this intervention and its benefits on hemoglobin optimization is a field of continuous debate and research [11,12].

With reference to the healing process after a major surgical intervention, research has shown that anemia and iron deficiency impair skin healing through secondary hypoxia [13] and low initial inflammatory reaction [14], leading to inferior local tension and expansion resistance [15]. At the bone level, these clinical entities are associated with low mineral density and, therefore, a low resistance to fracture [16], decreased osteogenesis [17], and increased resorption [18].

From our knowledge, no experimental study has carried out a complex analysis of the response to iron supplementation depending on the time of therapeutic intervention in the immediate perioperative period. We performed in vivo studies to create an experimental model of acute anemia associated with an iron deficiency by blood volume losses in subjects undergoing major surgery. The primary aim of this study was to identify the best perioperative time to correct an iron deficiency in order to improve the hematological status and recovery in an emergency setting using intravenous iron pharmacological agents. Thus, the weight, bioumoral determinations, and morpho-pathological findings were compared in accordance with the outcome, wound, and bone healing. The secondary aim was to assess the influence of iron administration on kidney function, considering that iron-induced renal impairment was noticed in previous experimental studies [19].

\section{Materials and Methods}

\subsection{Animal Care and Group Allocation}

The animal care and experimental procedures strictly followed the regulations of the Sanitary Veterinary and Safety Food Direction of Bucharest (DSVSA), Romania, which authorized the Emergency Clinical Hospital of Bucharest Experimental Lab (No. 481/13.11.2020). The experimental study also received the approval of the Ethical Committee of the Emergency Clinical Hospital of Bucharest (No. 10404/23.11.2020). All experiments were performed according to the Animal Care and Use Committee guidelines and recommendations. 
Healthy male adults Wistar rats, rattus norvegicus (INCD “Victor Babeș” Labs, Bucharest, Romania), with ages between 11 and 13 months, were left to acclimatize for 7 days. All animals were housed in polycarbonate cages (maximum 4 per cage), with sawdust bedding changed every three days under controlled environmental conditions (ambient humidity $40-60 \%$, temperature $23 \pm 2{ }^{\circ} \mathrm{C}$, and dark/light cycle of $12 \mathrm{~h}$ ), having access to standard food and water ad libitum.

After an adaptation period, thirty-five animals were randomly divided into six groups: group $0(n=5)$, the anemia model group (I) $(n=5)$, intraoperative iron group (II) $(n=7)$, 48-h postoperative iron group (III) $(n=7), 48$-h preoperative iron group (IV) $(n=5)$, and 7 days preoperative iron group $(\mathrm{V})(n=6)$. These specific perioperative times were chosen to mimic emergency settings. Group 0 is the control group for the accuracy of weight and blood tests without intervention, while group I served as the control group for comparison with the other intervention groups.

\subsection{Anemia Induction, Therapeutic Intervention, and Anesthetic and Surgical Procedures}

The model of iron deficiency anemia was obtained through acute bleeding (dissection in the cervical area, internal jugular vein catheterization, and removal of approximately $15 \%$ of the total blood volume) of each subject followed by major surgery. In the treatment groups (II-V), animals were treated with intravenous ferric carboxymaltose (Ferinject ${ }^{\circledR}$, Vifor Pharma, Paris, France) for iron deficiency, $20 \mathrm{mg} / \mathrm{kg}$, through internal jugular vein catheterization as follows: group II: intraoperative, group III: $48 \mathrm{~h}$ after surgery, group IV: $48 \mathrm{~h}$ before surgery, and group V: seven days before surgery (Figure 1).

\section{TIMING OF ANEMIA INDUCTION}

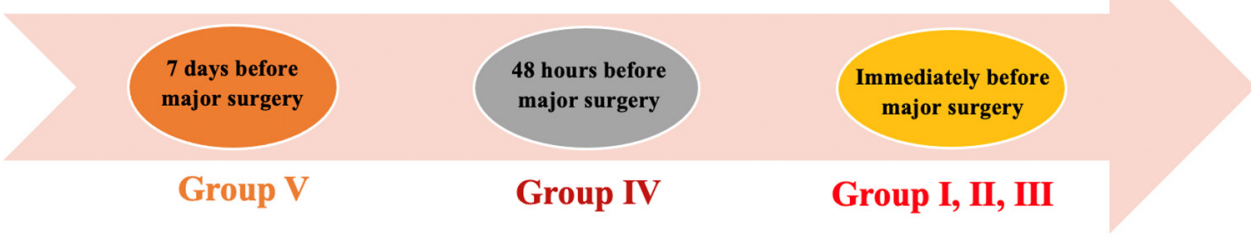

TIMING OF IRON ADMINISTRATION

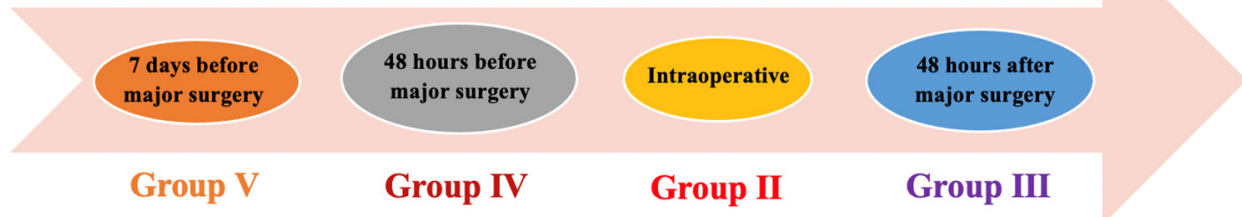

Figure 1. Timeline diagrams showing the time for anemia induction and iron administration in the studied groups. Legend: Group 0 is the control group without intervention for accuracy for weight and blood tests. Group I served as the control group for comparison with the other intervention groups.

All surgeries were performed under general anesthesia, starting with isoflurane $1 \%$ (Rompharm Company, Otopeni, Romania) in an induction room until reflexes abolition, followed by the intraperitoneal administration of ketamine (Panpharma, Luitre, France)/xylazine (Eurovet Animal Health, Bladel, The Netherlands) 40/5 mg/kg. Surgical intervention had the subsequent steps: skin incision, dissection of the anatomical planes and exposure of the femur, intraoperative femur fracture, open reduction and osteosynthesis using Kirschner wire, anatomical planes closing, and wound dressing. All the animals were operated by the same surgical team, which was blinded to the group allocation. Rig- 
orous hemostasis was obtained. Around $1 \mathrm{~mL}$ of blood loss was quantified using weighted gauzes. There were about four interventions/day with a duration of $50 \mathrm{~min}$.

\subsection{Clinical Evaluation}

After surgery, every subject was single-housed in a cage and observed for $12 \mathrm{~h}$. Weight was measured every two days after inducing anemia (day one for groups I-IV and day seven for group V) until day 7.

\subsection{Blood Sampling and Biomarkers Determination}

At the end of the experiment, the blood samples were collected. For iron profile determination, $2.4-2.6 \mathrm{~mL}$ of blood were collected in special tubes (PRIMA ${ }^{\circledR}$ Vacuum Tube) for the serum separation (centrifugation for $10 \mathrm{~min}$ at $4{ }^{\circ} \mathrm{C}$ and stored at $-20{ }^{\circ} \mathrm{C}$ until processing).

The level of ferritin and transferrin were measured using a semiautomatic biochemical analyzer (STAT FAX 303 PLUS $^{\circledR}$ ), as well as serum iron (A25 Biosystems ${ }^{\circledR}$ ). The total iron-binding capacity (TIBC) and transferrin saturation (TSAT) were obtained through specific formulas (Table 1) [20].

Table 1. Calculation formulas for the TSAT and TIBC.

\begin{tabular}{ccc}
\hline Parameter & Formula & Standard Measurement Unit \\
\hline TSAT & $=100 \times$ serum iron $/$ serum transferrin $\times 1.25$ & $\%$ \\
\hline TIBC & $=$ serum transferrin $(\mathrm{mg} / \mathrm{dL}) \times 1.25$ & $\mu \mathrm{g} / \mathrm{dL}$ \\
\hline
\end{tabular}

TSAT $=$ transferrin saturation and TIBC $=$ total iron binding capacity.

Hemoglobin $(\mathrm{Hb})$, hematocrit $(\mathrm{Ht})$, red blood cells (RBC), platelets (PLT), mean cell volume $(\mathrm{MCV})$, and mean cell hemoglobin $(\mathrm{MCH})$ were directly measured using a veterinary hematology analyzer (Exigo $\mathrm{H} 400$ System ${ }^{\circledR}$ ) after the tail puncture using manual micropipettes for minimal blood loss.

\subsection{Histology}

Promptly after blood sampling, at the end of the experiment (day seven: groups I-IV and day fourteen: group V), animals were sacrificed, and histological samples were harvested: the postoperative healed wound and surrounding skin, operated-on femur, and kidney. The samples were introduced in special recipients containing formol (Redmed Prodimpex, Bucharest, Romania) and left for fixation for $24 \mathrm{~h}$. Further, the bone samples were decalcified using a nitric acid solution $15 \%$ for $12 \mathrm{~h}$. Four micrometer sample slides were stained with hematoxylin and eosin (H\&E) then evaluated using an electronic microscope (Olympus BX43 $3^{\circledR}$ ) equipped with a digital camera. The collected data were analyzed using Olympus cellSens Dimension ${ }^{\circledR}$ software (version 1.13).

Three random images from each slide were photographed, and through a semiquantitative histopathological analysis, the lymphomonocyte inflammatory infiltrate (extremely rare cells, rare, and relatively frequent) and collagen deposition (minimal, moderate, and marked) were graded. Collagen dimension fiber was measured in ten different zones from each sample and compared. Kidney probes were assessed to identify the presence/absence of iatrogenic lesions following intravenous iron administration. Pathologists were blinded to the group allocation.

\subsection{Statistical Analysis}

The results of the present study were analyzed with MedCalc (version 14) and IBM SPSS Statistics 23 programs. The procedures used were descriptive statistics (for characterizing discrete and continuous variables defined in the database), graphs, parametric statistical tests (one-way ANOVA test with the Student-Newman-Keuls test for all pairwise comparisons). The significance level used for the one-way ANOVA test is $\alpha=0.05$. 
The adjusted significance level used for multiple comparisons is $\alpha^{\prime}=0.01$. According to the test used, a $p$-value less than $\alpha\left(\alpha^{\prime}\right)$ should be considered of statistical significance.

\section{Results}

Three experimental subjects were excluded: one for wound dehiscence (group II), one for self-skin injuries (group III), and one for refracture of the operated femur (group V).

\subsection{Clinical Findings}

Regarding the animal body weights, there was no significant difference between anemic and nonanemic groups over the seven days after the intervention $(p=0.931)$ (Table 2).

Table 2. Experimental subject mean weight variations during the study period.

\begin{tabular}{cccccccccc}
\hline Weight & $\begin{array}{c}\text { Day 1 (G-I-GIV) } \\
\text { (Day 7 for G-V) after Anemia and Surgery, } \\
\text { Reference Values for G-0 }\end{array}$ & \multicolumn{2}{c}{$\begin{array}{c}\text { Weight } \\
\text { Day 3 after } \\
\text { Surgery }\end{array}$} & \multicolumn{2}{c}{$\begin{array}{c}\text { Weight } \\
\text { Day 5 after } \\
\text { Surgery }\end{array}$} & $\begin{array}{c}\text { Weight } \\
\text { Day 7 after } \\
\text { Surgery }\end{array}$ \\
\hline Group & N & Mean & SD & Mean & SD & Mean & SD & Mean & SD \\
\hline G-I & 5 & 363 & 28 & 354 & 30 & 346 & 24 & 349 & 29 \\
\hline G-II & 6 & 350 & 29 & 340 & 31 & 336 & 33 & 343 & 28 \\
\hline G-III & 6 & 349 & 43 & 340 & 46 & 338 & 47 & 341 & 44 \\
\hline G-IV & 5 & 355 & 34 & 348 & 33 & 347 & 33 & 349 & 36 \\
\hline G-V & 5 & 364 & 33 & 358 & 32 & 357 & 31 & 359 & 32 \\
\hline G-0 & 5 & 340 & 44 & - & - & - & - & - \\
\hline & F-ratio & $(p)$ & $0.334(0.888)$ & & & $0.276(0.890)$ & $0.306(0.871)$ & $0.208(0.931)$ \\
\hline
\end{tabular}

* One-way ANOVA test. G-0: group 0, G-1: group I, G-II: group II, G-III: group III, G-IV: group IV, and G-V: group V.

\subsection{Routine Blood Tests}

At the end of the experiment (day seven or fourteen), the subject within group I presented the most modified red blood cell parameters (Table 3). According to ANOVA, at least two mean values were significantly different if the $p$-value $<0.05$ and to determine which mean values were different, the Student-Newman-Keuls test was applied.

Table 3. Effects of therapeutic intervention on routine blood test parameters (the results values are conferred as mean \pm SD).

\begin{tabular}{|c|c|c|c|c|c|c|}
\hline Group & $\mathrm{Hb}(\mathrm{g} / \mathrm{dL})$ & Ht (\%) & PLT $\left(10^{9} / \mathrm{L}\right)$ & $\operatorname{RBC}\left(10^{12} / \mathrm{L}\right)$ & MCH (pg) & MCV (fL) \\
\hline G-0 $(n=5)$ & $14.32 \pm 2.01$ & $36.88 \pm 4.81$ & $227.20 \pm 27.87$ & $7.64 \pm 0.94$ & $18.70 \pm 0.39$ & $48.28 \pm 0.98$ \\
\hline G-I $(n=5)$ & $10.4 \pm 0.54$ & $23.62 \pm 1.23$ & $518.80 \pm 56.53$ & $5.56 \pm 0.11$ & $18.44 \pm 0.54$ & $41.98 \pm 1.51$ \\
\hline G-II $(n=6)$ & $13.15 \pm 0.61$ & $34.58 \pm 1.15$ & $300 \pm 23.41$ & $7.01 \pm 0.32$ & $18.78 \pm 0.50$ & $49.25 \pm 2.38$ \\
\hline G-III $(n=6)$ & $12.2 \pm 0.33$ & $32.67 \pm 1.63$ & $277.33 \pm 43.54$ & $6.35 \pm 0.23$ & $19.32 \pm 0.67$ & $51.75 \pm 2.87$ \\
\hline G-IV $(n=5)$ & $12.72 \pm 0.54$ & $34.18 \pm 1.50$ & $276.60 \pm 33.66$ & $6.74 \pm 0.38$ & $18.94 \pm 0.77$ & $50.82 \pm 2.48$ \\
\hline $\mathrm{G}-\mathrm{V}(n=5)$ & $14.26 \pm 1.51$ & $37.34 \pm 3.43$ & $316.20 \pm 17.37$ & $7.56 \pm 0.78$ & $18.88 \pm 0.86$ & $49.56 \pm 3.40$ \\
\hline F-ratio $*(p)$ & $9.368(<0.001)$ & $18.768(<0.001)$ & $40.447(<0.001)$ & $11.031(<0.001)$ & $1.146(0.361)$ & $10.532(<0.001)$ \\
\hline $\begin{array}{c}\text { Group } 0 \\
\text { different from } \\
* *\end{array}$ & I, III & I & I, II, III, IV, V & I, III, IV & - & I \\
\hline
\end{tabular}

G-0: group 0, G-1: group I, G-II: group II, G-III: group III, G-IV: group IV, G-V: group V, Hb: hemoglobin, Ht: hematocrit, PLT: platelets, RBC: red blood cells, MCH: mean cell hemoglobin, and MCV: mean cell volume. ${ }^{*}$ One-way ANOVA test. ${ }^{* *}$ Student-Newman-Keuls test for all pairwise comparisons $(p<0.01)$. 


\subsection{Iron Profile}

The iron parameters that were investigated are presented in Table 4. Regarding the serum iron, the lowest value was registered in group I, followed by group IV. The lowest ferritin mean value was registered in group I, while the highest was registered in group III. The lowest value of transferrin was seen in group III, which was the closest to group 0. The lowest value of the TSAT was registered in group I, followed by group IV. The TIBC in group III was the closest to group 0.

Table 4. The effect of therapeutic intervention on the serum iron, ferritin, transferrin, TSAT, and TIBC (the results values are conferred as the mean $\pm \mathrm{SD}$ ).

\begin{tabular}{cccccc}
\hline Group & Serum Iron $(\mu \mathrm{g} / \mathrm{dL})$ & Ferritin $(\mathbf{n g} / \mathbf{m L})$ & Transferrin $(\mathbf{n g} / \mathbf{m L})$ & TSAT $(\%)$ & TIBC $(\mu \mathrm{g} / \mathrm{dL})$ \\
\hline G-0 $(n=5)$ & $60.50 \pm 2.34$ & $29.86 \pm 3.97$ & $67.54 \pm 7.14$ & $72.42 \pm 9.06$ & $84.38 \pm 8.95$ \\
\hline G-I $(n=5)$ & $27.04 \pm 6.92$ & $22.52 \pm 0.53$ & $88.28 \pm 7.65$ & $23.30 \pm 6.53$ & $110.36 \pm 9.59$ \\
\hline G-II $(n=6)$ & $61.50 \pm 11.43$ & $28.73 \pm 3.03$ & $71.85 \pm 9.74$ & $68.93 \pm 12.47$ & $89.80 \pm 12.18$ \\
\hline G-III $(n=6)$ & $55.95 \pm 7.26$ & $38.00 \pm 4.89$ & $71.05 \pm 6.65$ & $63.05 \pm 5.99$ & $88.77 \pm 8.30$ \\
\hline G-IV $(n=5)$ & $38.84 \pm 12.34$ & $27.34 \pm 4.01$ & $77.26 \pm 8.24$ & $40.20 \pm 13.01$ & $96.52 \pm 10.35$ \\
\hline G-V $(n=5)$ & $71.68 \pm 21.68$ & $28.38 \pm 1.59$ & $105.24 \pm 12.51$ & $56.62 \pm 13.89$ & $127.40 \pm 23.41$ \\
\hline F-ratio * $(p)$ & $9.887(<0.001)$ & $12.143(<0.001)$ & $13.353(<0.001)$ & $16.475(<0.001)$ & $8.182(<0.001)$ \\
\hline $\begin{array}{c}\text { Group 0 } \\
\text { different from }\end{array}$ & I, IV, V & I, III & I, V & I, IV, V & I, V \\
\hline TSAT: ta & & &
\end{tabular}

TSAT: transferrin saturation, TIBC: total iron-binding capacity, G-0: group 0, G-1: group I, G-II: group II, G-III: group III, G-IV: group IV, and G-V: group V. * One-way ANOVA test. ${ }^{* *}$ Student-Newman-Keuls test for all pairwise comparisons $(p<0.05)$.

\subsection{Morphopathological Findings}

\subsubsection{Wound Assessment}

Skin and skeletal muscle fragments associated with granulation tissue, which disrupts the muscular layer, were found. In the granulation tissue, small areas of gigantocellular inflammation were observed surrounding some bone fragments or hair follicles, more prominent in groups II, III, and V (Figure 2-Section A). All the samples revealed neovascularization, fibroblastic hyperplasia, stromal collagen deposits, and lymphomonocyte inflammatory infiltrate with mixt cellularity. Collagen deposition was considered moderate to the marked in groups V, III, and II and minimal-to-moderate in groups IV and I. About the lymphomonocyte inflammatory infiltrate, it was relatively frequent in groups V, II, and III, rare in group IV, and extremely rare in group I (Figure 2-Section B). The mean values of the collagen fiber dimensions were the highest in group $\mathrm{V}(6.15 \pm 2.34 \mu \mathrm{m})$, followed by group III $(4.54 \pm 0.95 \mu \mathrm{m})$ and group II $(4.45 \pm 0.92 \mu \mathrm{m})$, all within the normal limits for a newly closed wound. The lowest values were registered in group I $(4.12 \pm 0.92 \mu \mathrm{m})$ and group IV $(3.99 \pm 0.81 \mu \mathrm{m})(p=0.004)$ (Table 5). 


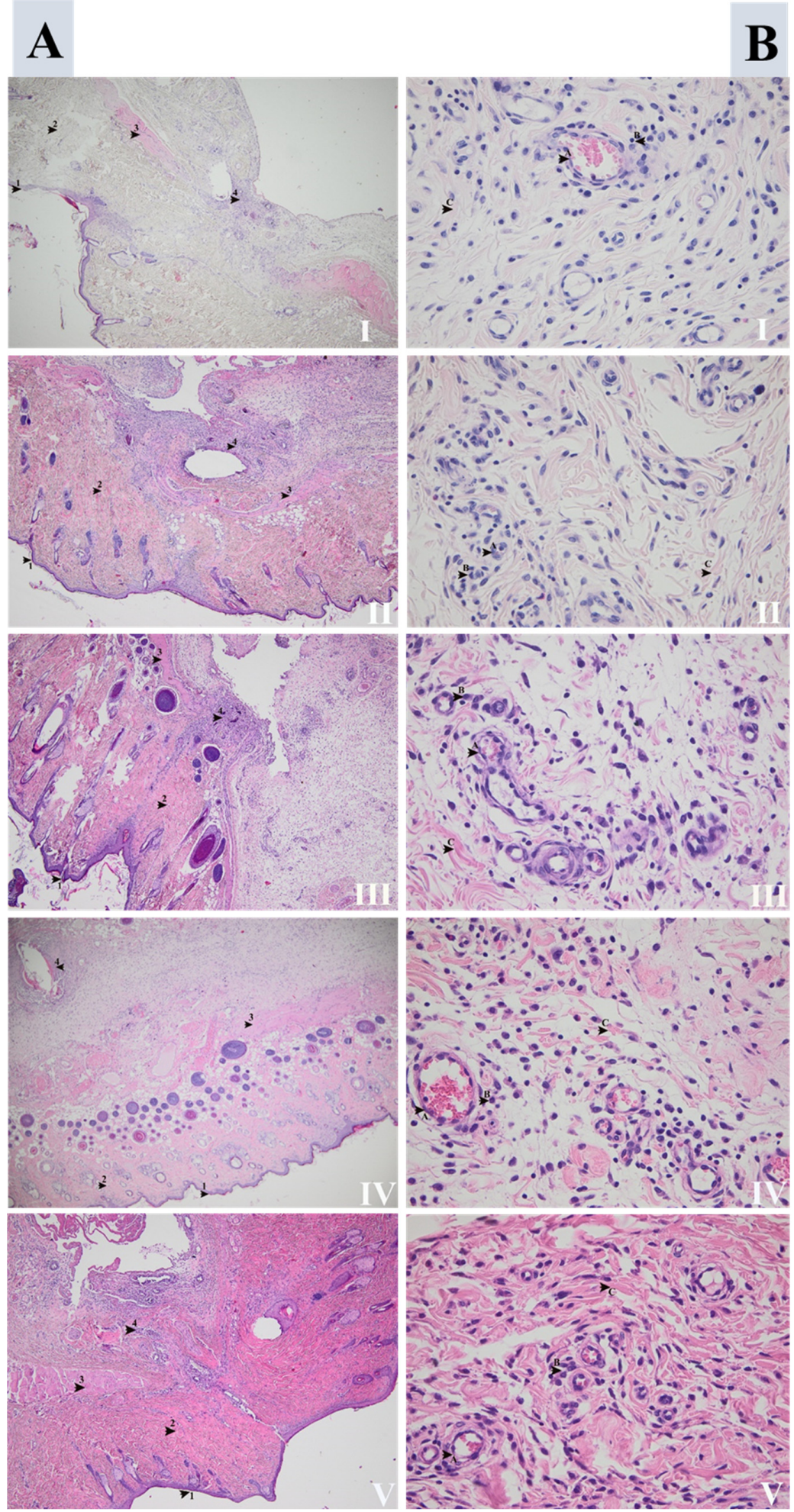

Figure 2. Skin repair after surgery in groups (I), (II), (III), (IV), and (V). (Section A) Overview: 1: epidermis, 2: dermis, 3: skeletal muscle, and 4: inflammatory infiltrate secondary to surgical incision (HE, 40×). (Section B) Detail images: (A) marks neovascularization more significant in groups (III), (V), and (II), followed by (IV) and (I). (B) Marks lymphomonocytes inflammatory infiltrates, better represented in groups (V), (III), and (II) compared with (IV) and (I). (C) Marks the collagen deposition that was moderate to marking in groups (V), (III), and (II), and minimal-to-moderate in groups (IV) and (I) $(\mathrm{HE}, 400 \times)$. 
Table 5. Collagen fiber dimension $(\mu \mathrm{m})$ mean values for the study groups $(\mathrm{I}-\mathrm{V})$ (the result values are conferred as the mean $\pm \mathrm{SD}$ ).

\begin{tabular}{ccc}
\hline Group & Collagen Fiber Dimension $(\mu \mathrm{mm})$ & Different from Group nr. $^{* *}$ \\
\hline G-I & $4.12 \pm 0.92$ & V \\
\hline G-II & $4.45 \pm 0.69$ & V \\
\hline G-III & $4.54 \pm 0.95$ & V \\
\hline G-IV & $3.99 \pm 0.81$ & V \\
\hline G-V & $6.15 \pm 2.34$ & I, II, III, IV \\
\hline F-ratio ${ }^{*}(p)$ & $4.549(0.004)$ & \\
\hline
\end{tabular}

G-1: group I, G-II: group II, G-III: group III, G-IV: group IV, and G-V: group V. * One-way ANOVA test. ${ }^{* *}$ Student-Newman-Keuls test for all pairwise comparisons $(p<0.01)$.

\subsubsection{Fracture Site Assessment}

The fracture site, periosteal reaction, and callus area for all the studied groups are presented in Figures 3-6. The periosteal reaction was observed, marked in groups II, III, and V (Figures 4 and 6), with thicker trabeculae compared to group IV and I (Figures 3 and 5). Taking into consideration the femur rat size, length of approximately $3.5 \mathrm{~cm}$ and thickness of $0.5 \mathrm{~cm}$, the bone healing process presented some particularities. The induced femur bone trauma through fracture associated with Kirschner wire placement led to a bone repair reaction (callus) extended through the wire length, not only in the fracture site. The trabeculae were thicker in groups II, III, and V (Figures 4 and 6) compared to groups IV and I, with a lesser degree of mineralization in the last (Figures 3 and 5).
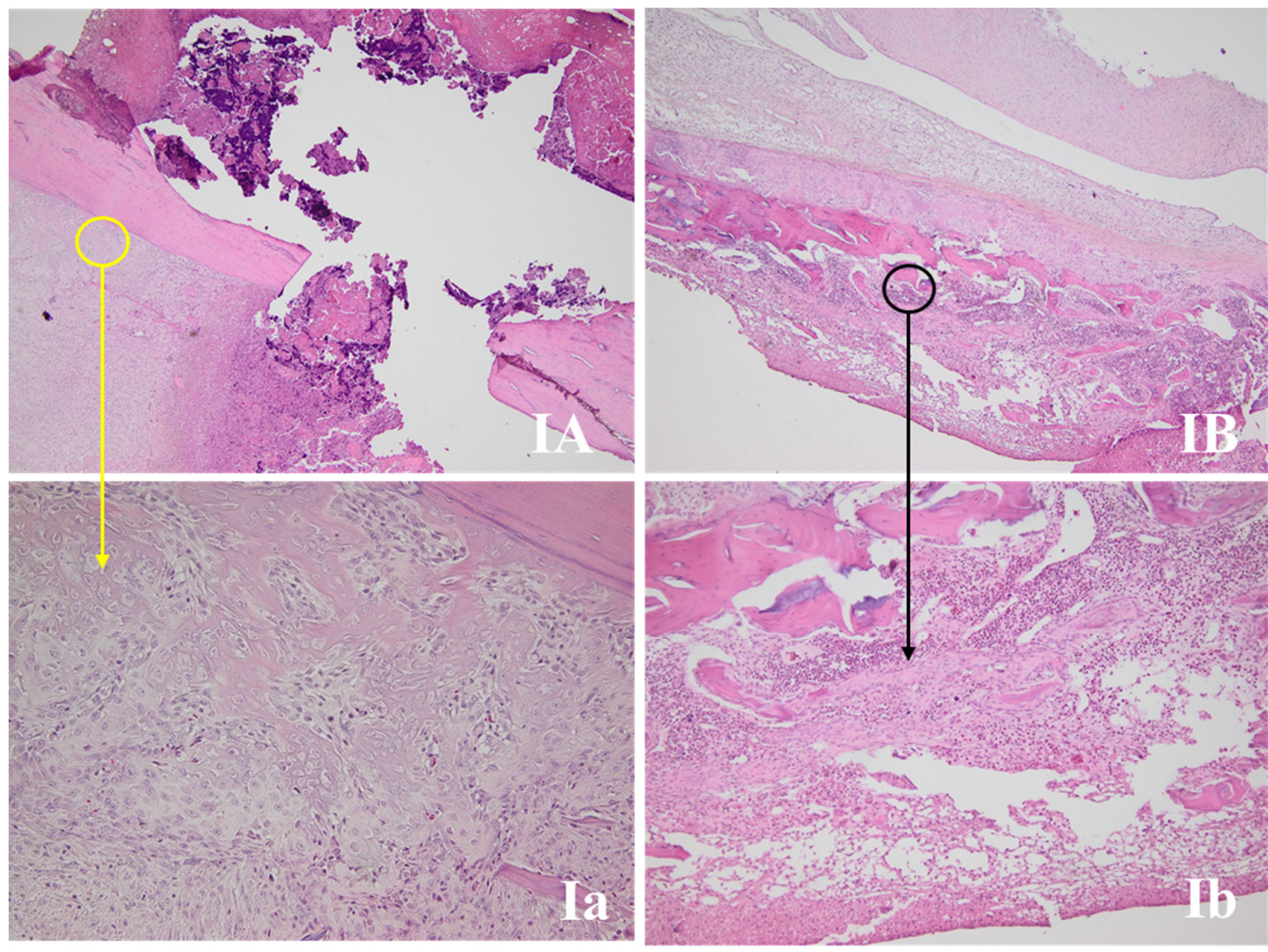

Figure 3. Bone repair of rat femurs in group I. (IA,B) present the fracture sites, with the yellow circle marking the periosteal reaction area and the black circle the bone repair reaction (callus) (HE, 40×). (Ia) Periosteal reaction with the thinnest trabeculae of all the samples (HE, 200×). (Ib) Thinner trabecular and a lesser degree of mineralization compared with the rest of the groups $(\mathrm{HE}, 100 \times)$. 

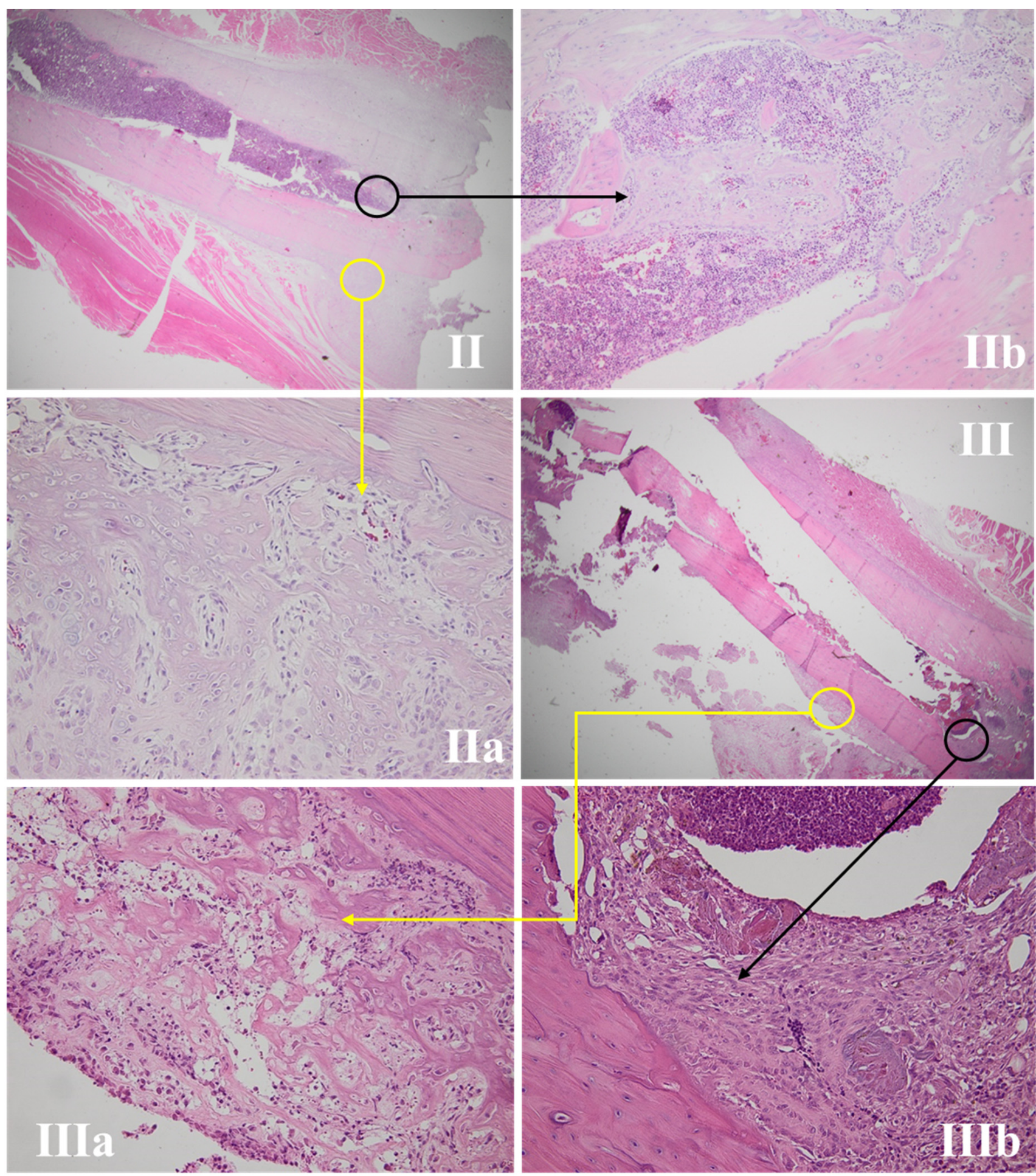

Figure 4. Bone repair of rat femur in groups II and III. (II,III) present the fracture sites, with the yellow circle marking a periosteal reaction area and the black circle marking the callus area (HE, 12.5 $\times$ ). (IIa,IIIa) expose the periosteal reaction, with the thickest trabeculae compared with groups IV and I and similar to group V (HE, 100 $\times$ ). (IIb,IIIb) show the bone repair reaction (callus), with thickest trabeculae and a better mineralization compared with groups IV and I and similar to group V (HE, 200×). 

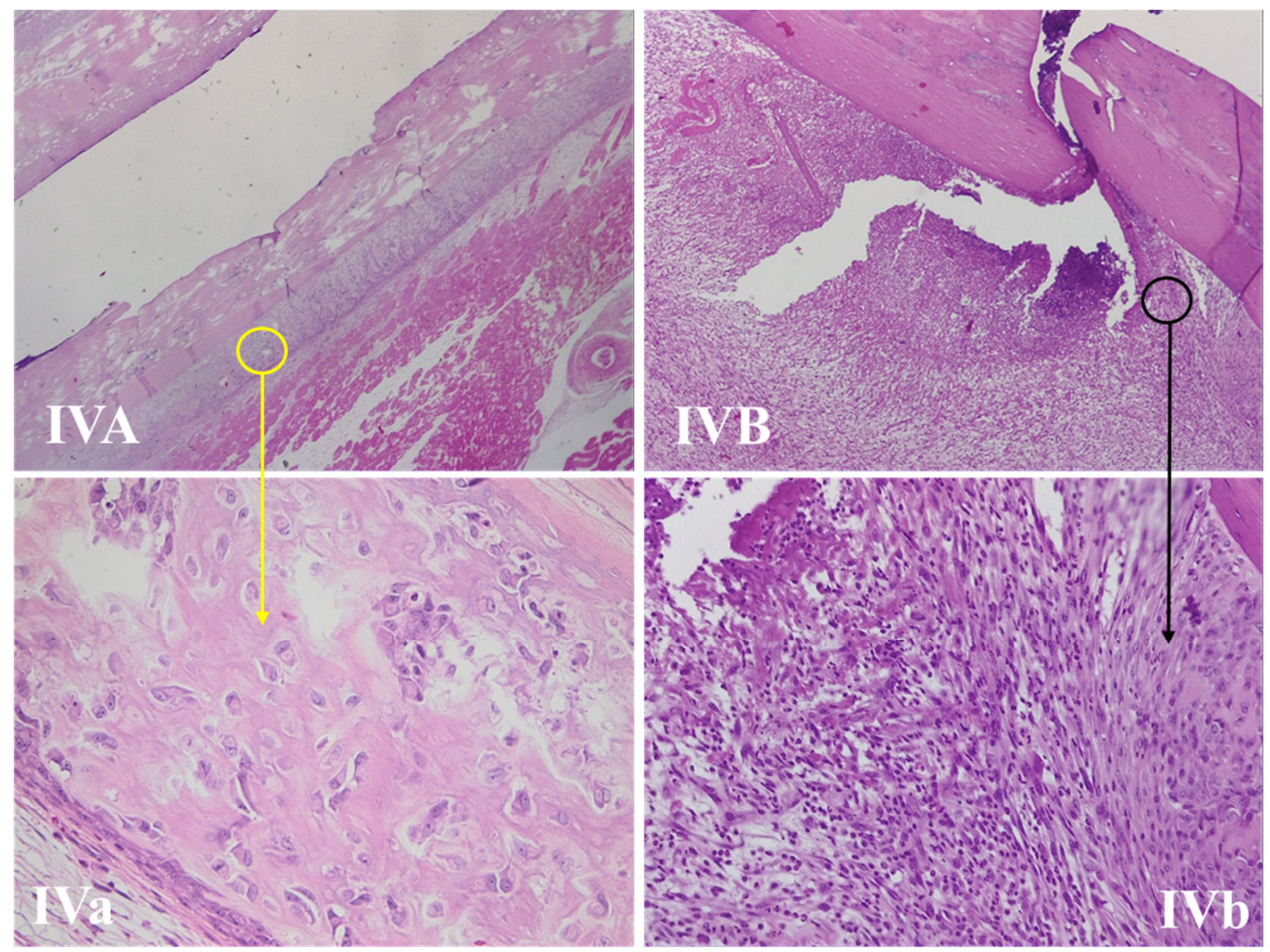

Figure 5. Bone repair of a rat femur in group IV. (IVA,B) The fracture sites, with the yellow circle marking the periosteal reaction area and the black circle marking the bone repair reaction (callus) (HE, 50×). (IVa) Periosteal reaction with the thinnest trabeculae compared with groups II, III, and V (HE, 400×). (IVb) Thinner trabecular and a lesser degree of mineralization compared with groups II, III, and V (HE, 400×). 


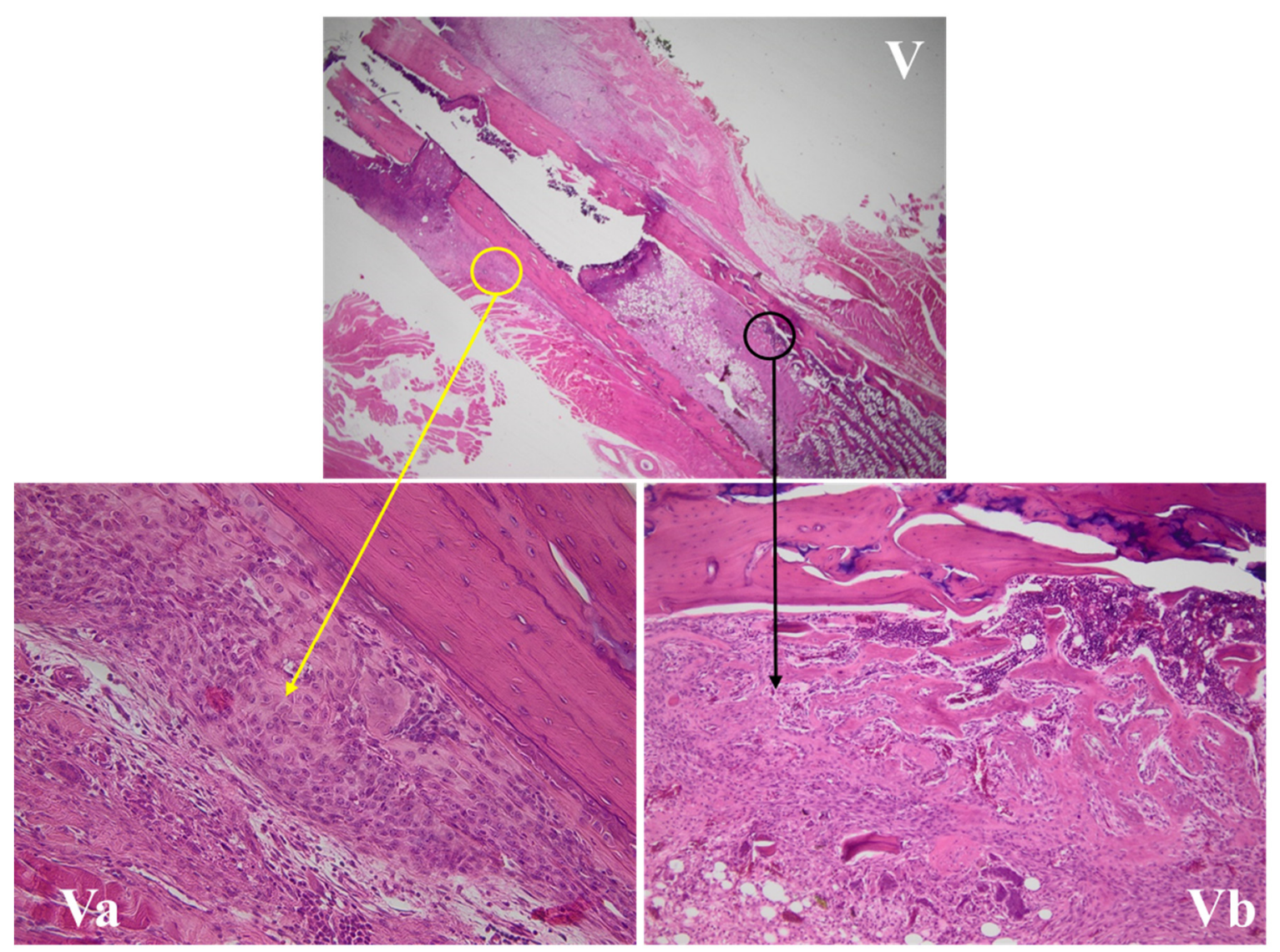

Figure 6. Bone repair of a rat femur in group V. (V) The fracture site, with the yellow circle marking a periosteal reaction area and the black circle the callus area $(\mathrm{HE}, 12.5 \times)$. (Va) The periosteal reaction, with the thickest trabeculae compared with groups IV and I and similar to groups II and III (HE, 200×). (Vb) The bone repair reaction (callus), with the thickest trabeculae and a better mineralization compared with groups IV and I, and similar to groups II and III (HE, 400×).

\subsubsection{Kidney Histological Assessment}

No iron deposits or any renal injuries were identified in either of the groups (Figure 7).
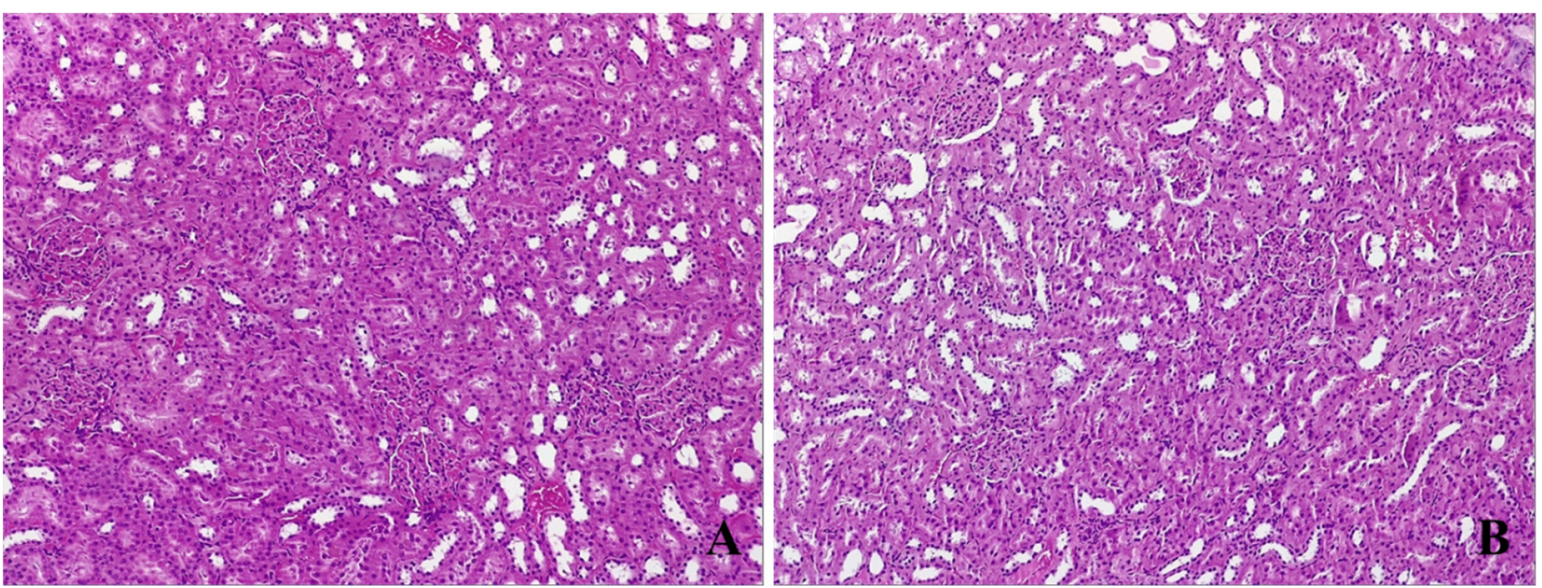

Figure 7. Renal samples: (A) anemic subject and (B) subject that received ferric carboxymaltose. The histological assessment shows no renal injury or iron deposition in these tissues regarding the iron administration or the time of intervention (HE, $100 \times)$. 


\section{Discussion}

This study researched the proper time to administer intravenous iron in order to correct perioperative anemia and, thus, to improve the hemoglobin level in acute settings no longer than seven days before surgery or $48 \mathrm{~h}$ postoperative. To achieve that, we analyzed the weight, bioumoral markers, and histological skin and bone healing after a surgical trauma, and we observed that performing this intervention seven days before surgery, intraoperatively, or $48 \mathrm{~h}$ after surgery led to better results compared with $48 \mathrm{~h}$ before surgery or not performing it at all.

We obtained an iron deficit model associated with anemia by acute blood loss, a feasible experimental method according to the published data [21]. Specific indications were followed for group allocation [22], and all the possible variables were reduced to a minimum to respect the general recommendation regarding experimental animal studies $[23,24]$. This model was sustained by the fact that, in group I, the serum iron was lower than in group 0 , the same as for the hemoglobin and ferritin values. In addition, the normal clinical examination and level of leucocytes, along with low ferritin in the anemic group and not higher than expected in the intervention group, were markers of infection absence [25].

Iron is an essential element involved in development and growth [26]. Animal studies have shown that iron deficiency leads to weight loss in anemic subjects after 9 days and becomes significant after around 17 days [21]. It is also a feature of chronic iron deficiency, especially through deprivation $[27,28]$. In our study, there were no differences regarding the animals' weights, probably in relation with the acute nature of the events. Acute anemia and iron deficiency have unspecific symptoms like physical fatigue and decreased effort capacity [29,30], which may be thoroughly investigated in future research.

This study showed that seven days after an important blood loss, followed by major surgery, the hemoglobin, hematocrit, and red blood cells (sensitive and specific indices of anemia [31]) were significantly lower in group I compared with the groups where a therapeutic intervention was performed. The $\mathrm{MCV}$ and $\mathrm{MCH}$ values were close to group 0 in the subjects receiving intravenous iron, implying that, through a proper therapeutic intervention, the erythrocyte dimensions and hemoglobin content can be restored.

Another important finding was represented by higher platelets values in group I, significantly modified compared with the other groups. An analysis published by Hung et al. showed that the risk of adverse thromboembolic events grows from $7.8 \%$ to $15.8 \%$ in patients with thrombocytosis and iron deficiency [32]. Therefore, in patients undergoing major surgery, which itself induces a hypercoagulable state, the prompt correction of iron deficiency decreases this risk.

Clinical trials targeting postoperative wound healing are scarce and usually evaluate the local tissue strength $[33,34]$. In experimental studies, subjects with iron deficits induced by iron-free food products presented a lower tension and expansion resistance compared with nonanemic animals [35,36]. Immediately after injury (days one to seven), a primary local inflammatory state develops (abundant local neutrophils, monocytes, macrophages, and lymphocytes) [15], followed by neovascularization initiation [37]. From day four, the proliferative phase begins, with fibroblasts initiating collagen synthesis and deposition [38]. During the healing process, the amount of collagen and normal development of its fiber length and organization are responsible for the wound strength [37].

We observed that seven days after surgery, the neovascularization was more significant in group III, followed by groups V and II. Fewer neutrophils and a well-represented inflammatory infiltrate with lymphomonocytes were noticed in groups III, V, and II. The mean dimension values of the collagen fibers were the biggest in group $\mathrm{V}$, followed by groups III and II. All of the above support the hypothesis that the wound healing process at seven days postoperative presents the best features in groups V, III, and II, while group I presents the lowest progress.

In bone tissue, iron is involved in the structure of some enzymes that synthesize collagen [39] and in vitamin D metabolism [40]. There are few clinical or experimental 
studies analyzing the interconnection between the iron status and bone healing, especially rapidly after an injury or a surgical procedure. Some studies have shown that low levels of ferritin are associated with low bone mineral density [41] or that an iron deficiency induces bone resorption acceleration [18]. After an injury, blood vessels and normal bone architecture disruption start an inflammatory cascade, with local hematoma formation [42]. Consequently, devitalized bone resorption starts, followed by neovascularization, new bone formation on either side of the fracture site with a callus appearance [43], cartilaginous tissue, mineralization, and bone remodeling [44]. In this study, the periosteal reaction presented thicker trabeculae in groups II, III, and V, compared with groups IV and I. The same aspects were observed at the callus area, with a higher degree of mineralization being noticed in groups II, III, and V in comparison with the anemic group (I) and group IV. Therefore, it can be stated that correcting iron deficiency through an intraoperative or 48-h postoperative intervention presents a more favorable bone-healing trend in comparison with the other studied groups.

Studies have shown that many iron-containing intravenous agents have metabolites with renal excretion, therefore having the potential of producing nephrotoxicity through oxidative stress [45]. In order to test our secondary hypothesis, a renal histopathological assessment was performed, and no kidney injury was observed in group I, nor in any subject receiving intravenous ferric carboxymaltose.

The study limitations counted the small number of subjects per group that could impair the statistical power and the short duration of the experiment. Additionally, using specific markers for inflammation and infections will increase the value of the research. Further investigation of these aspects above the acute perioperative period (7 days after surgery) will help compare the long-term benefits of these interventions.

\section{Conclusions}

This study presents an original experimental model of acute induced anemia and iron deficiency through blood loss followed by major surgery. From our knowledge, it is the first experimental study to assess the effect of perioperative intravenous iron administration in an emergency setting at a specific time by comparing the weight, hematological, and iron status-defining parameters, as well as the histological characteristics of the included subjects seven days after surgery. Rapidly correcting the iron deficiency leads to a favorable improvement of hemoglobin, iron homeostasis and clinical outcome in surgical subjects. The present findings show that, by correcting the iron deficiency through intravenous iron administration 7 days before surgery, intraoperative, or $48 \mathrm{~h}$ postoperatively, a better clinical outcome is achieved, including a better healing process evolution of postoperative wounds and bone fractures compared to the anemic group and subjects that received therapeutic intervention $48 \mathrm{~h}$ before surgery.

Author Contributions: Conceptualization, M.T.; Data curation, I.P., S.A.Z. and I.A.C.; Formal analysis, I.P., L.C.P., A.N. and I.A.C.; Investigation, M.T., T.P.N., A.T., S.A.Z. and I.A.C.; Methodology, M.T., T.P.N., I.P., A.N. and I.A.C.; Project administration, M.T.; Resources, S.A.Z.; Supervision, I.A.C. and I.M.G.; Validation, I.A.C.; Writing—original draft, M.T. and T.P.N.; Writing-review and editing, M.T., T.P.N., I.P., A.N. and I.A.C. All authors have read and agreed to the published version of the manuscript.

Funding: This research received no external funding.

Institutional Review Board Statement: The animal care and experimental procedures strictly followed the regulations of the Sanitary Veterinary and Safety Food Direction of Bucharest (DSVSA), Romania, which authorized the Emergency Clinical Hospital of Bucharest Experimental Lab (No. 481/13.11.2020). The experimental study received the approval of the Ethical Committee of the Emergency Clinical Hospital of Bucharest (No. 10404/23.11.2020).

Informed Consent Statement: Not applicable. 
Acknowledgments: This study is part of Mirela Tigliș' PhD thesis. Ileana Peride and Andrei Niculae provided substantial contributions to the conception of the work, interpretation of the data, revising it critically for important intellectual content, and approval of the final manuscript version.

Conflicts of Interest: The authors declare no conflict of interest.

\section{References}

1. Muñoz, M.; Acheson, A.G.; Bisbe, E.; Butcher, A.; Gómez-Ramírez, S.; Khalafallah, A.A.; Kehlet, H.; Kietaibl, S.; Liumbruno, G.M.; Meybohm, P.; et al. An international consensus statement on the management of postoperative anaemia after major surgical procedures. Anaesthesia 2018, 73, 1418-1431. [CrossRef] [PubMed]

2. Girelli, D.; Ugolini, S.; Busti, F.; Marchi, G.; Castagna, A. Modern iron replacement therapy: Clinical and pathophysiological insights. Int. J. Hematol. 2018, 107, 16-30. [CrossRef]

3. Bacuzzi, A.; Dionigi, G.; Piffaretti, G.; Tozzi, M.; Del Romano, M.; Guzzetti, L.; Paracchini, F.; Villa, F.; Cuffari, S. Preoperative Methods to Improve Erythropoiesis. Transplant. Proc. 2011, 43, 324-326. [CrossRef]

4. Pasricha, S.-R.; Flecknoe-Brown, S.C.; Allen, K.; Gibson, P.R.; McMahon, L.P.; Olynyk, J.K.; Roger, S.D.; Savoia, H.F.; Tampi, R.; Thomson, A.R.; et al. Diagnosis and management of iron deficiency anaemia: A clinical update. Med. J. Aust. 2010, 193, 525-532. [CrossRef] [PubMed]

5. Deloughery, T.G. Safety of Oral and Intravenous Iron. Acta Haematol. 2019, 142, 8-12. [CrossRef]

6. Litton, E.; Xiao, J.; Allen, C.T.; Ho, K.M. Iron-Restricted Erythropoiesis and Risk of Red Blood Cell Transfusion in the Intensive Care Unit: A Prospective Observational Study. Anaesth. Intensive Care 2015, 43, 612-616. [CrossRef] [PubMed]

7. Elstrott, B.; Khan, L.; Olson, S.; Raghunathan, V.; Deloughery, T.; Shatzel, J.J. The role of iron repletion in adult iron deficiency anemia and other diseases. Eur. J. Haematol. 2020, 104, 153-161. [CrossRef]

8. Yoon, B.-H.; Lee, B.S.; Won, H.; Kim, H.-K.; Lee, Y.-K.; Koo, K.-H. Preoperative Iron Supplementation and Restrictive Transfusion Strategy in Hip Fracture Surgery. Clin. Orthop. Surg. 2019, 11, 265-269. [CrossRef]

9. Kam, P.M.-H.; Chu, C.W.-H.; Chan, E.M.-Y.; Liu, O.-L.; Kwok, K.-H. Use of intravenous iron therapy in colorectal cancer patient with iron deficiency anemia: A propensity-score matched study. Int. J. Colorectal Dis. 2020, 35, 521-527. [CrossRef]

10. Elhenawy, A.M.; Meyer, S.R.; Bagshaw, S.M.; MacArthur, R.G.; Carroll, L.J. Role of preoperative intravenous iron therapy to correct anemia before major surgery: A systematic review and meta-analysis. Syst. Rev. 2021, 10, 36. [CrossRef]

11. Peters, F.; Ellermann, I.; Steinbicker, A.U. Intravenous Iron for Treatment of Anemia in the 3 Perisurgical Phases: A Review and Analysis of the Current Literature. Anesth. Analg. 2018, 126, 1268-1282. [CrossRef]

12. Jeong, J.H.; Chang, M.J.; Kang, S.-B.; Park, H.J.; Lee, K.H.; Chang, C.B. Postoperative Intravenous Iron Supplementation Does Not Improve Hemoglobin Level and Transfusion Rate Following Staged Bilateral Total Knee Arthroplasty. J. Arthroplast. 2020, 35, 2444-2450. [CrossRef] [PubMed]

13. Hong, W.X.; Hu, M.S.; Esquivel, M.; Liang, G.Y.; Rennert, R.C.; McArdle, A.; Paik, K.J.; Duscher, D.; Gurtner, G.C.; Lorenz, H.P.; et al. The Role of Hypoxia-Inducible Factor in Wound Healing. Adv. Wound Care 2014, 3, 390-399. [CrossRef]

14. Takayama, Y.; Aoki, R. Roles of lactoferrin on skin wound healing. Biochem. Cell Biol. 2011, 90, 497-503. [CrossRef]

15. Sandberg, N.; Zederfeldt, B. Influence of acute hemorrhage on wound healing in the rabbit. Acta Chir. Scand. 1960, 118, 367-371.

16. Katsumata, S.-I.; Katsumata-Tsuboi, R.; Uehara, M.; Suzuki, K. Severe Iron Deficiency Decreases Both Bone Formation and Bone Resorption in Rats. J. Nutr. 2009, 139, 238-243. [CrossRef] [PubMed]

17. Zhao, G.-Y.; Zhao, L.-P.; He, Y.-F.; Li, G.-F.; Gao, C.; Li, K.; Xu, Y.-J. A Comparison of the Biological Activities of Human Osteoblast hFOB1.19 Between Iron Excess and Iron Deficiency. Biol. Trace Elem. Res. 2012, 150, 487-495. [CrossRef]

18. Wright, I.; Blanco-Rojo, R.; Fernández, M.C.; Toxqui, L.; Moreno, G.; Pérez-Granados, A.M.; De La Piedra, C.; Remacha, Á.F.; Vaquero, M.P. Bone remodelling is reduced by recovery from iron-deficiency anaemia in premenopausal women. J. Physiol. Biochem. 2013, 69, 889-896. [CrossRef] [PubMed]

19. Walker, V.J.; Agarwal, A. Targeting iron homeostasis in acute kidney injury. In Seminars in Nephrology; WB Saunders: Philadelphia, PA, USA, 2016; Volume 36, pp. 62-70.

20. Total Iron Binding Capacity (TIBC), Transferrin and Transferrin Saturation. Available online: https://labpedia.net/total-ironbinding-capacity-tibc-transferrin-and-transferrin-saturation/ (accessed on 12 February 2021).

21. Ma, J.; Wen, X.; Mo, F.; Wang, X.; Shen, Z.; Li, M. Effects of Different Doses and Duration of Iron Supplementation on Curing Iron Deficiency Anemia: An Experimental Study. Biol. Trace Elem. Res. 2014, 162, 242-251. [CrossRef] [PubMed]

22. Sample Size Calculations (IACUC). Available online: http://www.bu.edu/researchsupport/compliance/animal-care/workingwith-animals/research/sample-size-calculations-iacuc/ (accessed on 24 January 2021).

23. O’Connell, K.E.; Mikkola, A.M.; Stepanek, A.M.; Vernet, A.; Hall, C.D.; Sun, C.C.; Yildirim, E.; Staropoli, J.F.; Lee, J.T.; Brown, D.E. Practical Murine Hematopathology: A Comparative Review and Implications for Research. Comp. Med. 2015, 65, 96-113. [PubMed]

24. Knoblaugh, S.E.; Hohl, T.M.; La Perle, K.M.D. Pathology Principles and Practices for Analysis of Animal Models. ILAR J. 2018, 59, 40-50. [CrossRef] [PubMed]

25. Liu, C.-P.; Liu, Z.-Y.; Liu, J.-P.; Kang, Y.; Mao, C.-S.; Shang, J. Diagnostic Value of Common Inflammatory Markers on Fever of Unknown Origin. Jpn. J. Infect. Dis. 2016, 69, 378-383. [CrossRef] 
26. Hassan, T.H.; Badr, M.A.; Karam, N.A.; Zkaria, M.; El Saadany, H.F.; Abdel Rahman, D.M.; Shahbah, D.A.; Al Morshedy, S.M.; Fathy, M.; Esh, A.M.H.; et al. Impact of iron deficiency anemia on the function of the immune system in children. Medicine 2016, 95, e5395. [CrossRef]

27. Wang, F.-R.; Xie, Z.-G.; Ye, X.-Q.; Deng, S.-G.; Hu, Y.Q.; Guo, X.; Chen, S.G. Effectiveness of treatment of iron deficiency anemia in rats with squid ink melanin-Fe. Food Funct. 2014, 5, 123-128. [CrossRef]

28. He, H.; An, F.; Huang, Q.; Kong, Y.; He, D.; Chen, L.; Song, H. Metabolic effect of AOS-iron in rats with iron deficiency anemia using LC-MS/MS based metabolomics. Food Res. Int. 2020, 130, 108913. [CrossRef] [PubMed]

29. Houston, B.L.; Hurrie, D.; Graham, J.; Perija, B.; Rimmer, E.; Rabbani, R.; Bernstein, C.N.; Turgeon, A.F.; Fergusson, D.A.; Houston, D.S.; et al. Efficacy of iron supplementation on fatigue and physical capacity in non-anaemic iron-deficient adults: A systematic review of randomised controlled trials. BMJ Open 2018, 8, e019240. [CrossRef]

30. Wenger, M.J.; Dellavalle, D.M.; Murray-Kolb, L.E.; Haas, J.D. Effect of iron deficiency on simultaneous measures of behavior, brain activity, and energy expenditure in the performance of a cognitive task. Nutr. Neurosci. 2019, 22, 196-206. [CrossRef]

31. Murphy, J.F. Haemoglobin Concentrations for the Diagnosis of Anaemia and Assessment of Severity. Vitamin and Mineral Nutrition Information System; WHO/NMH/NHD/MNM/11.1; World Health Organization: Geneva, Switzerland, 2011. Available online: http:/ / www.who.int/vmnis/indicators/haemoglobin.pdf (accessed on 2 May 2021).

32. Anderson, F.A., Jr.; Spencer, F.A. Risk Factors for Venous Thromboembolism. Circulation 2003, 107, I9-I16. [CrossRef]

33. Jonsson, K.; Jensen, J.A.; Goodson, W.H., 3rd; Scheuenstuhl, H.; West, J.; Hopf, H.W.; Hunt, T.K. Tissue Oxygenation, Anemia, and Perfusion in Relation to Wound Healing in Surgical Patients. Ann. Surg. 1991, 214, 605-613. [CrossRef]

34. Pavlidis, T.E.; Galatianos, I.N.; Papaziogas, B.T.; Lazaridis, C.N.; Atmatzidis, K.S.; Makris, J.G.; Papaziogas, T.B. Complete Dehiscence of the Abdominal Wound and Incriminating Factors. Eur. J. Surg. 2001, 167, 351-354. [CrossRef]

35. Oliveira Sampaio, S.C.P.; de C. Monteiro, J.S.; Cangussú, M.C.T.; Pires Santos, G.M.; dos Santos, M.A.; dos Santos, J.N.; Pinheiro, A.L. Effect of laser and LED phototherapies on the healing of cutaneous wound on healthy and iron-deficient Wistar rats and their impact on fibroblastic activity during wound healing. Lasers Med. Sci. 2013, 28, 799-806. [CrossRef] [PubMed]

36. Cañedo-Dorantes, L.; Cañedo-Ayala, M. Skin Acute Wound Healing: A Comprehensive Review. Int. J. Inflamm. 2019, 2019, 3706315. [CrossRef] [PubMed]

37. Jørgensen, L.N. Collagen deposition in the subcutaneous tissue during wound healing in humans: A model evaluation. APMIS Suppl. 2003, 115, 1-56.

38. Greaves, N.S.; Ashcroft, K.J.; Baguneid, M.; Bayat, A. Current understanding of molecular and cellular mechanisms in fibroplasia and angiogenesis during acute wound healing. J. Dermatol. Sci. 2013, 72, 206-217. [CrossRef] [PubMed]

39. Shoulders, M.D.; Raines, R.T. Collagen Structure and Stability. Ann. Rev. Biochem. 2009, 78, 929-958. [CrossRef] [PubMed]

40. Pikuleva, I.A.; Waterman, M.R. Cytochromes P450: Roles in Diseases. J. Biol. Chem. 2013, 288, 17091-17098. [CrossRef]

41. D'Amelio, P.; Cristofaro, M.A.; Tamone, C.; Morra, E.; Di Bella, S.; Isaia, G.; Grimaldi, A.; Gennero, L.; Gariboldi, A.; Ponzetto, A.; et al. Role of iron metabolism and oxidative damage in postmenopausal bone loss. Bone 2008, 43, 1010-1015. [CrossRef]

42. Kolar, P.; Schmidt-Bleek, K.; Schell, H.; Gaber, T.; Toben, D.; Schmidmaier, G.; Perka, C.; Buttgereit, F.; Duda, G.N. The Early Fracture Hematoma and Its Potential Role in Fracture Healing. Tissue Eng. Part B Rev. 2010, 16, 427-434. [CrossRef]

43. Shapiro, F. Bone development and its relation to fracture repair. The role of mesenchymal osteoblasts and surface osteoblasts. Eur. Cells Mater. 2008, 15, 53-76. [CrossRef]

44. Marsell, R.; Einhorn, T.A. The biology of fracture healing. Injury 2011, 42, 551-555. [CrossRef]

45. Cavdar, C.; Temiz, A.; Yeniçerioğlu, Y.; Çalişkan, S.; Çelik, A.; Sifil, A.; Önvural, B.; Camsari, T. The Effects of Intravenous Iron Treatment on Oxidant Stress and Erythrocyte Deformability in Hemodialysis Patients. Scand. J. Urol. Nephrol. 2003, 37, 77-82. [CrossRef] [PubMed] 